\title{
Relationship between Dyslipidemia and Glycemic Status in Type-2 Diabetes Mellitus
}

MITUL NAVINCHANDRA CHHATRIWALA', MEGHA P PATEL ${ }^{2}$, DHARMIK SAVJIBHAI PATEL ${ }^{3}$, HITESH N SHAH $^{4}$

\section{ABSTRACT}

Introduction: India has among the largest number of diabetic subjects in the world. Dyslipidemia is a lipoprotein metabolic abnormality leading to a persistent increase in the plasmatic concentration of cholesterol and triglycerides. Studies found that increased triglyceride levels and decreased HDL cholesterol levels predicted Coronary Heart Disease (CHD). HDL may be the most consistent predictor of CHD in type 2 diabetes subjects, followed by triglyceride and total cholesterol.

Aim: To assess the link between HDL/LDL ratio and diabetic status of patients and to compare $\mathrm{HbA} 1 \mathrm{c}$ and FBS with HDL/ LDL ratio.

Materials and Methods: This was a retrospective crosssectional study done over a period of 1 year; in the clinical biochemistry department of a tertiary care rural centre. Before starting the study, the protocol was prepared and presented to Institutional Human Research Ethics Committee which was subsequently approved. The data for 101 diabetic patients and 106 non-diabetics were considered, who attended the hospital for their routine health check-up. The following were noted from the online data centre and filled into a proforma-FBS, PP2BS, HbA1c, HDL, LDL, Tc/HDL, HDL/LDL. p-value of less than 0.05 was considered statistically significant.

Results: There was significant increase in the levels of FBS and $\mathrm{HbA} 1 \mathrm{c}$ in diabetic group compared to the control group. The level of HDL gradually decreased, the level of LDL increased, while the HDL: LDL ratio significantly was less in the diabetic group.

Conclusion: It can be concluded that diabetes mellitus type 2 is strongly associated with lower level of high density lipoprotein and higher level of low density lipoprotein cholesterol due to which there is alteration in the HDL/LDL ratio.

\section{INTRODUCTION}

Diabetes has been described as "One of the main threats to human health in the twenty first century [1]. US Centre for Disease Control showed that there were 5.5 million diabetics in 1980 that increased to 21.1 million in 2010. This increase mirrors the increasing prevalence of obesity. Worldwide, there is a projected increase in the prevalence of diabetes from 382 million (8.3\%) in 2013 to 592 million (10.1\%) in 2035 [2].

Chronic hyperglycemia, dyslipidemia of diabetes is associated with long-term damage, dysfunction, and failure of various organs, especially the eyes, kidneys, nerves, heart, and blood vessels.[3] Secondary dyslipidemia occurs due to hypothyroidism, obstructive liver disease, obesity, diabetes mellitus, pregnancy, chronic renal failure, alcohol, cigarette, smoking, bypass surgery, stress. [4] Diabetic dyslipidemia is a condition where the good cholesterol (HDL) levels are decreased and raise triglyceride and bad cholesterol (LDL), which increase the risk for heart disease and stroke [5].

Type 2 diabetics are usually dyslipidemic even if under relative good glycemic control. Elevated triglycerides, decreased high-density lipoprotein cholesterol and elevated small dense low-density lipoprotein cholesterol are risk factors for atherosclerosis in type 2 diabetes [6].

The cardiovascular complication of diabetes is the leading cause of death in people with diabetes. Of these CVD, coronary heart disease and stroke are the most common causes [7]. There are many risk factors for CVD but the most significant is abnormal lipid values [8]. Recent study reported that insulin increases the number of LDL receptor, so chronic insulin deficiency might be associated with a diminished level of LDL receptor. In these cases also, increase in LDL particles results in increase in LDL cholesterol value in diabetes mellitus [9]. In diabetes mellitus, the rise in plasma cholesterol level is due to an increased hepatic production of VLDL or decreased removal of VLDL from the circulation [10].

Recent studies have demonstrated that in diabetic patients Triglyceride (TG) level is a risk factor for CVD independent of HDL-C level and despite glycemic control, the incidence of macrovascular disease is increased two to five-fold in diabetics as compared to non-diabetic patients. This is attributed mainly to diabetic dyslipidemia [11].

Hypertriglyceridemia often is rather modest. In non-diabetic individuals, renal disease, hypothyroidism and genetically determined lipoprotein disorders effect the lipid levels; while in T2DM, the obesity/insulin-resistance lead to lipid abnormalities independently of hyperglycemia. In T2DM, this phenotype is not usually fully corrected with glycemic control, suggesting that insulin resistance is associated with this lipid abnormality. An increase in triglyceride rich lipoproteins is commonly associated with a reduction in HDL and an increase in small dense LDL levels [12].

VLDL1 is a strong determinant of plasma triglyceride concentration and has been shown to relate to insulin sensitivity as measured by HOMA-IR. In insulin resistant individuals, VLDL1 is secreted in excess while the secretion of VLDL2 is comparable to that in insulinsensitive individuals [13]

In the Framingham Heart Study, $13 \%$ of men and $24 \%$ of women with diabetes mellitus had increased total plasma cholesterol levels, compared with $14 \%$ of men and $21 \%$ of women without diabetes mellitus [14]. By contrast, the prevalence of high plasma triglyceride levels in individuals with diabetes mellitus (19\% in men and $17 \%$ in women) was significantly higher than in those without diabetes mellitus ( $9 \%$ of men and $8 \%$ of women).

Many studies found that diabetes and dyslipidemia overlap and that they together accelerate the process of atherogenesis as a result. [15]. Together they increase cardiovascular risk and form a 
vicious circle in which dyslipidemia worsens diabetes and diabetes worsens dyslipidemia.

The Strong Heart Study showed that there is a stepwise decrease in LDL size according to diabetic status from normal to impaired glucose tolerance, and then to diabetes. This association is more striking in women than in men, which may be the reason why diabetic women lose their sex-specific cardio-protection even at concentrations well below the National Cholesterol Education Program (NCEP) [16].

Low density lipoprotein-cholesterol is a strong independent predictor of $\mathrm{CHD}$ in patients with $\mathrm{DM}$, particularly when components of diabetic dyslipidemia are present. A low level of HDL-C under $40 \mathrm{mg} / \mathrm{dl}(<1 \mathrm{mmol} / \mathrm{l})$ is an independent risk factor for CVD. In diabetic dyslipidemia, the concentration of HDL-C is reduced and its compositions as well as distribution are changed. However, when obesity and hypertriglyceridemia were absent, HDL2-C levels in the diabetic population were not significantly different from controls [17].

At present, LDL-cholesterol remains a strong independent predictor of CVD in diabetic patients, even when the LDL level is below the national cholesterol education program target of $130 \mathrm{mg} / \mathrm{dl}$. The strong heart study observed a 12\% increase in CVD risk in diabetic subjects with every $10 \mathrm{mg} / \mathrm{dl}$ increase in LDL-cholesterol. Varbo A et al., showed that with each $1 \mathrm{mmol} / \mathrm{l}$ increase in non-fasting remnant cholesterol there was a 2.8 fold causal risk for ischemic heart disease, independent of HDL reduction $[18,19]$.

Diabetics with $\mathrm{HbA} 1 \mathrm{c}>8 \%$ show a $150 \%$ increased risk of death from heart disease. The Adult Treatment Panel III (NCEP) recommend treating diabetics with hyperlipidaemia [20]. A previous study concluded that increased triglyceride levels and decreased HDL cholesterol levels predicted CHD in T2DM subjects [21]. The United Kingdom Prospective Diabetes Study (UKPDS) showed that both decreased HDL and elevated LDL predicted CHD. HDL may be the most consistent predictor of CHD in type 2 diabetes subjects, followed by triglyceride and total cholesterol [22].

Elevated $\mathrm{HbA} 1 \mathrm{c}$ is also regarded as an independent risk factor for cardiovascular disease in diabetics as well as non-diabetics. [23]. The risk of cardiovascular disease increases by $18 \%$ for each $1 \%$ increase in absolute $\mathrm{HbA1c}$. Besides this, the $\mathrm{HbA1c}$ and cardiovascular disease correlation is known among non-diabetic cases [24].

Considering the above scenario, it was aimed in the study, to find out the association between various clinical and laboratory parameters of diabetic patients and effects of dyslipidemia in comparison with non-diabetic patients.

\section{MATERIALS AND METHODS}

This was a retrospective cross-sectional study done over a period of 1 year (January 2018 to December 2018). The study was done in the clinical biochemistry department, Shree Krishna Hospital (tertiary care rural centre), Pramukh Swami Medical College, Karamsad.

The study was approved by the Institutional Human Research Ethics Committee (IEC/HMPCMCE/87/Faculty/8/10/18).

Data for 101 diabetics and 106 non-diabetics were taken for the study, out of the total 278 . These patients reported to the hospital for routine health check-up. The data were present online in the hospital portal. The FBS, PP2BS, HbA1c, HDL, LDL, Tc/HDL, HDL/ $\mathrm{LDL}$, besides the demographic information were taken and filled into a proforma.

\section{Exclusion Criteria}

- $\quad$ Patients with chronic renal disease, liver cirrhosis, cancer.

- Patients taking anti-lipidemic drugs

- Patients on alcohol.
As per hospital protocol, HbA1c was measured by the Turbidometric inhibition immunoassay (TINIA), fasting blood glucose by the hexokinase method and AHDL method-Bichromatic endpoint for measuring the HDL.

\section{STATISTICAL ANALYSIS}

Analysis was performed using the commercially available statistical software stata 14. For each analyte, Mean $\pm S D$ values were presented. $\mathrm{p}$-value of less than 0.05 was considered statistically significant.

\section{RESULTS}

This study comprised of 207 individual (101 case and 106 controls). Among 101 case group had 60 males and 41 females [Table/Fig-1].

There was significant increase in the levels of FBS, HbA1c and LDL while a decrease in HDL in diabetic group [Table/Fig-2].

\begin{tabular}{|l|c|c|c|}
\hline Age (years) & Total & Male & Female \\
\hline $20-40$ & 6 & 4 & 2 \\
\hline $41-60$ & 43 & 24 & 19 \\
\hline 61 -above & 52 & 32 & 20 \\
\hline Total & 101 & 60 & 41 \\
\hline
\end{tabular}

\begin{tabular}{|c|c|c|c|c|}
\hline Paratmeter & Group & Mean value & Standard deviation & $p$-value \\
\hline FBS (mg/dL) & $\begin{array}{l}\text { Diabetic } \\
\text { Control }\end{array}$ & $\begin{array}{c}182.3861 \\
93.4528\end{array}$ & $\begin{array}{c}86.98850 \\
5.86049\end{array}$ & $<0.001$ \\
\hline $\mathrm{HbA} 1 \mathrm{c}$ & $\begin{array}{l}\text { Diabetic } \\
\text { Control }\end{array}$ & $\begin{array}{l}8.2812 \\
5.5792\end{array}$ & $\begin{array}{l}1.63479 \\
0.35071\end{array}$ & $<0.001$ \\
\hline $\mathrm{HDL}(\mathrm{mg} / \mathrm{dL})$ & $\begin{array}{l}\text { Diabetic } \\
\text { Control }\end{array}$ & $\begin{array}{l}45.7426 \\
53.8962\end{array}$ & $\begin{array}{l}11.36279 \\
19.57497\end{array}$ & $<0.001$ \\
\hline HDL/LDL ratio & $\begin{array}{l}\text { Diabetic } \\
\text { Control }\end{array}$ & $\begin{array}{l}0.5452 \\
0.6132\end{array}$ & $\begin{array}{l}0.32507 \\
0.40083\end{array}$ & 0.18 \\
\hline
\end{tabular}

There was a significant positive linear correlation between $\mathrm{HbA} 1 \mathrm{c}$ and fasting blood sugar $(r=0.661, p=0.0001)$ while negative correlation between glucose and HDL-C ( $r=-179, p=0.0001)$. Negative correlation was also found between $\mathrm{HbA} 1 \mathrm{c}$ and $\mathrm{HDL}-\mathrm{C}$ $(r=-175, p=0.0001)$.

\section{DISCUSSION}

The present study was designed to investigate the HDL/LDL ratio and their relationship with glycemic status in the diabetes mellitus of type 2. The HDL/LDL was considered as an indicator for cardiovascular diseases. There was a significant decrease in HDL level among diabetics as compared to the control group. Lower HDL cholesterol level is attributed to triglyceride enrichment by cholesterol ester transfer protein and increased hepatic triglyceride lipase activity. Elevated lipid and lipoprotein level were found in diabetic patients which may be due to insulin resistance because impaired insulin action increase free fatty acid release from intra-abdominal adipose tissue, promoting lipoprotein lipase activity which results in reduced triglyceride clearance [10].

There was a significant positive linear correlation between elevated blood glucose and total cholesterol, triglycerides, LDL, HBA1C and negative correlation between glucose and HDL-C. This is an important finding which shows that hyperglycemia is closely associated with hypercholesterolemia, hypertriglyceridemia, elevated LDL, and reduced HDL which are all documented as risk factors for CHD.

Therefore, diabetic patients with lack of diabetic control (high FBS) have higher lipids, less HDL cholesterol. This also points to the significance of control of blood glucose in diabetic patients.

Thus the results of this study clearly indicate that there is strong association between the levels of $\mathrm{HbA} 1 \mathrm{c}$ and HDL: LDL ratio. The levels of the Hb1Ac were found significantly higher in the diabetic 
Sample size

Findings

\begin{tabular}{|c|c|c|}
\hline Author name & Sample size & Findings \\
\hline Gowtham K et al., [26] & $\begin{array}{l}\text { Case-control } \\
30 \text { T2DM-30 Non diabetic }\end{array}$ & $\begin{array}{l}\mathrm{HDL} \text { and } \mathrm{LDL} \text { cholesterol levels and correlated HDL/LDL ratio with } \mathrm{HbA1c} \\
\text { levels and fasting blood glucose. } \mathrm{HDL} \text { and } \mathrm{LDL} \text { cholesterol levels and correlated } \\
\mathrm{HDL} / \mathrm{LDL} \text { ratio with } \mathrm{HbA1c} \text { levels and fasting blood glucose }\end{array}$ \\
\hline Lorenzo C et al., [15] & $\begin{array}{l}\text { Epidemiological study } \\
1107 \text { individuals with impaired glucose tolerance (IGT) } \\
\text { and impaired fasting glucose (IFG) }\end{array}$ & $\begin{array}{l}\text { triglyceride was high in isolated IGT, and high-density lipoprotein cholesterol } \\
\text { was low in combined IFG/IGT }\end{array}$ \\
\hline Klisic $A$ et al., [27] & $\begin{array}{l}\text { Cross sectional study } \\
275 \text { T2DM individuals }\end{array}$ & $\begin{array}{l}\text { Total cholesterol; and LDL cholesterol are independent predictors of higher } \\
\text { HBA1c, and as they increased by } 1 \mathrm{mmol} / \mathrm{L} \text { each, probabilities of higher } \\
\text { HBA1c increased by } 30 \%, 34 \% \text {, and } 42 \% \text {, respectively }\end{array}$ \\
\hline Sirsikar M et al., [28] & $\begin{array}{l}\text { Case-control } \\
75 \text { T2DM-75 Non diabetic }\end{array}$ & $\begin{array}{l}\text { HbA1c showed direct and significant correlations with cholesterol, triglycerides } \\
\text { and LDL and inverse correlation with } \mathrm{HDL} \text { in cases }\end{array}$ \\
\hline Devkar $\vee$ et al., [29] & $\begin{array}{l}\text { Retrospective cross sectional study } \\
100 \text { T2DM individuals }\end{array}$ & $\begin{array}{l}\text { Both HBA1C and FBG exhibited direct correlations with cholesterol, TG, and } \\
\text { LDL and inverse correlation with HDL. The levels of serum cholesterol and TG } \\
\text { were significantly higher and of HDL significantly lower in patients with worse } \\
\text { glycemic control as compared to patients with good glycemic control. }\end{array}$ \\
\hline Yadav $\mathrm{N}$ et al., [30] & $\begin{array}{l}\text { Cross sectional study } \\
\text { Group I ( } 73 \text { individuals with good glycemic control HbA1C } \\
6-7 \mathrm{gm} \%) \text {, group II ( } 69 \text { individuals with fair glycemic } \\
\text { control HbA1C } 7.1-8.2 \mathrm{gm} \% \text { ) and group III ( } 69 \text { individuals } \\
\text { with poor glycemic control, HbA1C >8.2 gm\%) }\end{array}$ & $\begin{array}{l}\text { TG level was maximum in group III, LDL level was highest in group III, HDL was } \\
\text { lowest in group III. A significant positive correlation was observed between } \\
\text { level of TG and HbA1C. a positive correlation was observed between } \mathrm{LDL} \text { and } \\
\mathrm{HbA1C} \text {. a negative correlation was seen between } \mathrm{HDL} \text { and } \mathrm{HbA1C}\end{array}$ \\
\hline Sreenivas Reddy A et al., [31] & 490 T2DM individuals & $\begin{array}{l}\text { The level of } \mathrm{HbA1c} \text { showed a direct significant correlation with TC, TG, LDL, } \\
\text { but did not correlate with } \mathrm{HDL}\end{array}$ \\
\hline Artha IMJR et al., [32] & $\begin{array}{l}\text { Retrospective study } \\
140 \text { T2DM individuals }\end{array}$ & $\begin{array}{l}\text { A significant positive correlation between } \mathrm{LDL} \text {, total cholesterol, } \mathrm{LDL}-\mathrm{C}, \mathrm{TG} \text {, and } \\
\text { TC to HDL-C ratio, triglycerides, and TC/HDL-C ratio with HBA1c level were } \\
\text { found. A negative correlation was observed on HDL-C with the HBA1c level. }\end{array}$ \\
\hline Patel DK et al., [33] & 50 T2DM individuals & $\begin{array}{l}\text { HbA1c level showed the direct correlation with level of LDL-C, TG, and TC } \\
\text { while it had negative correlation with high-density lipoprotein }\end{array}$ \\
\hline Valarmathi A et al., [34] & 35 T2DM individuals & HbA1c correlated with raised LDL, raised TG and low HDL. \\
\hline Naqvi S et al., [35] & $\begin{array}{l}\text { Cross-sectional study } \\
509 \text { T2DM individuals }\end{array}$ & $\begin{array}{l}\text { With HbA1c cut-off value of } 7 \%, 74 \% \text { patients had high triglycerides and } \\
\text { showed a significant association with high triglyceride levels }\end{array}$ \\
\hline Prabhavathi K et al., [36] & 130 T2DM individuals & HbA1c showed direct and significant correlations with cholesterol, TG and LDL \\
\hline
\end{tabular}

group. Similarly, the ratio of HDL: LDL was also altered due to the low levels of the protective high density lipoproteins. The results were similar to the previous studies done by Indumati $V$ et al, though they have taken LDL: HDL as the parameter because in their study the ratio was increased [25].

Patients with type 2 diabetes mellitus are at an increased risk of cardiovascular morbidity and mortality. The significant increase in Fasting blood sugar, $\mathrm{Hb} 1 \mathrm{Ac}$ and alterations in protective $\mathrm{HDL}$ and bad LDL of diabetic patients when compared to the control predicts that patients with type 2 Diabetes mellitus are at a higher risk level for CHD.

The [Table/Fig-3] enlists some of the studies on diabetic dyslipidemia.

\section{LIMITATION}

The retrospective nature of the study limits its relevance.

\section{CONCLUSION}

High glycated hemoglobin (>7.0\%) correlated with high lipid profile values and low glycated hemoglobin value $(<7.0 \%)$ correlated with low Lipid profile values. Thus, HbA1c can be used as a potential biomarker for predicting dyslipidemia in type 2 diabetic patients in addition to glycemic control. Hence early diagnosis can be accomplished through relatively inexpensive blood testing and may be utilised for screening high-risk diabetic patients for timely intervention with lipid lowering drugs.

\section{REFERENCES}

[1] Zimmet P, Alberti KGMM, Shaw J. Global and societal implications of the diabetes epidemic. Nature 2001 Dec 13;414:782-87.

[2] World health organization. (2004). Global strategy on diet, physical activity and health. Fifty-Seventh World Health Assembly, WHA57.17.Geneva. Available on: http://www.goforyourlife.vic.gov.au/hav/admin.nsf/images/ WHO_Global_Strategy.pdf.

[3] American Diabetes Association. Diagnosis and Classification of Diabetes Mellitus. Diabetes Care January 2004; 27:s5-s10.

[4] National Cholesterol Education Program. Third report of the national cholestero education program (NCEP) expert panel on detection, evaluation, and treatment of high blood cholesterol in adults. NIH 2002 Sep.
[5] International Journal of Vascular Medicine Volume 2017. https.//doi. org/10.1155/2017/60661306.

[6] Meshram A, Kachhawa K, Gujar V, Bokariya P. Correlation of diabetes dyslipidemia and type 2 diabetes mellitus amongst the people of Vidharba region of India. IOSR Journal of Pharmacy. 2016;6(1):45-50.

[7] World Health Organization. 2007. Cardiovascular diseases. Available on: http:// www.who.int/mediacentre/factsheets/fs317/en/print.html.

[8] Hobbs F. Cardiovascular diasease: different strategies for primary and secondary prevention?. Heart. 2004;90(10):1217-23.

[9] Suryawanshi NP, Bhutey AK, Nagdeote AN, Jadhav AA, Manoorkar GS. The study of lipid peroxide and lipid profile in diabetes mellitus. Indian Journal of Clinical Biochemistry. 2006;21(1):126-30.

[10] Ganong WF. Review of Medical Physiology 21 . Endocrine Function of pancreas \& Regulation of Carbohydrate Metabolism. 2003;324-33.

[11] Stamler J, Vaccaro O, Neaton JD, Wentworth D. Diabetes, other risk factors, and 12 year cardiovascular mortality for men screened in the Multiple Risk Factor Intervention trial. Diabetes Care. 1993;16:434-44.

[12] Shah S, Casas JP, Drenos F, Whittaker J, Deanfield J, Swerdlow DI et al. Causal relevance of blood lipid fractions in the development of carotid atherosclerosis: Mendelian randomization analysis. Circ Cardiovasc Genet 2013;6(1):63-72.

[13] Caron S, Verrijken A, Mertens I, Samanez CH, Mautino G, Haas JT, et al. Transcriptional activation of apolipoprotein CIII expression by glucose may contribute to diabetic dyslipidemia. Arterioscler Thromb Vasc Biol 2011;31(3):513-19.

[14] Mahmood SS, Levy D, Vasan RS, Wang TJ. The Framingham Heart Study and the epidemiology of cardiovascular disease: a historical perspective. Lancet 2014;383(9921):999-1008. doi:10.1016/S0140-6736(13)61752-3.

[15] Lorenzo C, Hartnett S, Hanley AJ, Rewers MJ, Wagenknecht LE, Karter AJ. Impaired fasting glucose and impaired glucose tolerance have distinct lipoprotein and apolipoprotein changes: the insulin resistance atherosclerosis study. J Clin Endocrinol Metab 2013;98(4):1622-30.

[16] Graham I, Atar D, Borch-Johnsen K. European guidelines on cardiovascular disease prevention in clinical practice: executive summary. Eur. Heart J. 2007; $28,2375-2414$

[17] Rashid S, Barrett PH, Uffelman KD. Lipolytically modified triglyceride-enriched HDLs are rapidly cleared from the circulation. Arterioscler. Thromb. Vasc. Biol. 2002;22:483-87.

[18] Varbo A, Benn M, Tybjaerg-Hansen A, et al. Remnant cholesterol as a causal risk factor for ischemic heart disease. J Am Coll Cardiol 2013:61(4):427-36.

[19] Barter PJ, Caulfield M, Eriksson M, Grundy SM, Kastelein JJ, Komajda M et al. Effects of torcetrapib in patients at high risk for coronary events. N Engl $\mathrm{J}$ Med 2007;357(21):2109-22.

[20] National Cholesterol Education Program (2002) Third Report of the National Cholesterol Education Program (NCEP) Expert Panel on Detection, Evaluation, and Treatment of High Blood Cholesterol in Adults (Adult Treatment Panel III) Fina report. Circulation; 106: 3143. 
[21] American diabetes association. Management of dyslipidemia in adults with diabetes. Diabetes Care 2003 Jan;26 Suppl 1:83-86.

[22] Stratton IM, Adler Al, Neil HAW, Matthews DR, Manley SE, Cull CA et al. Association of glycaemia with macrovascular and microvascular complications of type 2 diabetes (UKPDS 35): prospective observational study. BMJ 2000;321:405-12.

[23] Almdal T., Scharling H., Jensen J.S., Vestergaard H. (2004) The independent effect of type 2 diabetes mellitus on ischemic heart disease, stroke, and death: a population-based study of 13,000 men and women with 20 years of follow-up. Arch Intern Med. 164:1422-26.

[24] Britton KA, Pradhan AD, Gaziano JM, Manson JE, Ridker PM, et al. Hemoglobin A1c, Body Mass Index and the Risk of Hypertension in Women. American Journal of Hypertension. 2011;24(3):328-34. doi:10.1038/ajh.2010.233.

[25] Indumati V, Patil V, Krishnaswamy D, Satishkumar D, Vijay V, Mahesh S. Etal. NonHDL cholesterol and LDL-C/HDL-C ratio in type II diabetic patients. International Journal of Pharma and Bio Sciences. 2011;2:71-77.

[26] Gowtham K, Gandhe MB, SalweKJ, SrinivasanAR. HDL/LDL ratio as a risk factor in type 2 diabetes mellitus. Adv Lab Med Int. 2012; 2(1):09-18.

[27] Klisic A, Kavaric N, Jovanovic M, Zvrko E, Skerovic V, Scepanovic A. Association between unfavorable lipid profile and glycemic control in patients with type 2 diabetes mellitus. J Res Med Sci. 2017;22:122

[28] Sirsikar M, Supriya S, Mohanty S, Pinnelli VBK. Role of glycated hemoglobin (HBA1c) as a dual marker to predict glycemic status and dyslipidemia in type II diabetes mellitus. Int J Res Med Sci. 2016 Oct;4(10):4524-29.
[29] Devkar V Desai P, Prajapati P, Rao S, Desai A. Correlation between Glycated Hemoglobin and Dyslipidemia in Patients with Type 2 Diabetes Mellitus in a Tertiary Care Hospital, Maharashtra, India. Int J Sci Stud 2016;4(6):121-24.

[30] Yadav N, Singh S, Gupta S, Mishra S, Singh K. Correlation between glycemic control and dyslipidemia in Type 2 Diabetes Mellitus patient. Int J Basic Clin Pharmacol 2019;8:1387-92.

[31] Sreenivas Reddy A, Meera S, William E, Kumar JS. Correlation between glycemic control and lipid profile in type 2 diabetic patients: $\mathrm{HbA} 1 \mathrm{c}$ as an indirect indicator of dyslipidemia Asian J Pharm Clin Res. 2014;7(2):153-55

[32] Artha IMJR, Bhargah A, Dharmawan NK, Pande UW, Triyana KA, Mahariski PA. High level of individual lipid profile and lipid ratio as a predictive marker of poor glycemic control in type-2 diabetes mellitus. Vascular Health and Risk Management. 2019;15:149-57

[33] Patel DK, Gamit DN, Patel AB, Gohil BH. Glycosylated hemoglobin as a marker of dyslipidemia in type 2 diabetes mellitus patients in a tertiary care hospital. Natl J Physiol Pharm Pharmacol 2017;7(1):113-18

[34] Valarmathi A, Sastri L. Glycosylated hemoglobin as a marker of dyslipidemia in type 2 diabetes mellitus patients in a tertiary care hospital. IAIM, 2017;4(2):21-25.

35] Naqvi S, Naveed S, Ali Z, AhmadSM, Khan RA, Raj H et al. Correlation between Glycated Hemoglobin and Triglyceride Level in Type 2 Diabetes Mellitus. Cureus. 2017;9(6):e1347.

[36] Prabhavathi K, Kirthana Kunikullaya U, Jaisri Goturu. Glycosylated Haemoglobin (HbA1c)-A Marker of Circulating Lipids in Type 2 Diabetic Patients. J Clin Diagn Res. 2014;8(2):20-23.

\section{PARTICULARS OF CONTRIBUTORS:}

1. Assistant Professor, Department of Biochemistry, Pramukhswami Medical College, Karamsad, Gujarat, India

2. MSc. (CLT), Department of Biochemistry, Pramukhswami Medical College, Karamsad, Gujarat, India.

3. Associate Professor, Department of Biochemistry, Pramukhswami Medical College, Karamsad, Gujarat, India.

4. Professor and Head, Department of Biochemistry, Pramukhswami Medical College, Karamsad, Gujarat, India.

NAME, ADDRESS, E-MAIL ID OF THE CORRESPONDING AUTHOR:

Dharmik Savjibhai Patel,

Department of Biochemistry, Karamsad, Gujarat, India.

E-mail: dharmiksp@charutarhealth.org

Date of Submission: Sep 20, 2019

Date of Peer Review: Sep 26, 2019

Date of Acceptance: Oct 04, 2019

FINANCIAL OR OTHER COMPETING INTERESTS: None.

Date of Publishing: Nov 01, 2019 